\title{
Tipping Points: A Statistical Comparison between Humans and Conodonts
}

\section{Qualls C1, Lucas SG ${ }^{2}$, Ali $\mathrm{AM}^{3}$ and Appenzeller $\mathrm{O}^{4,5 *}$}

${ }^{1}$ Department of Mathematics and Statistics, University of New Mexico, Albuquerque, NM, USA

${ }^{2} \mathrm{New}$ Mexico Museum of Natural History and Science, Albuquerque, NM, USA

${ }^{3}$ Department of Earth and Planetary Sciences, University of New Mexico, Albuquerque, NM, USA

${ }^{4} \mathrm{New}$ Mexico Health Enhancement and Marathon Clinics Research Foundation, Albuquerque, NM, USA

${ }^{5}$ New Mexico Museum of Natural History and Science, Albuquerque, NM, USA

\begin{abstract}
We analyzed Conodonts and rocks using Inductively Coupled Plasma-Optical Emission Spectroscopy (ICP-OES) using statistical methods to compare the tipping points for arsenic $(\mathrm{As})$ and lead $(\mathrm{Pb})$ in conodonts and contemporaneous human tissues. We found that ancient seas contained high levels of As which also occurred in Conodont teeth and which was leached from rocks; a biogenic enrichment. We show that there is a significant decline in reaching the tipping point with time $(P=0.01)$ implying that the sources of these neurotoxic metals in modern teeth have decreased such that $\mathrm{Pb}$ and As no longer accumulate in human apatite as it did in the apatite of Conodont teeth. The probability of exceeding the tipping point increases significantly with increasing As concentration $(P=0.01)$ and increasing $P b$ concentration $(P=0.04)$ This suggests that the toxic effects of these metals may be additive.
\end{abstract}

Keywords: Conodont; Biogenic enrichment; Neurotoxic metals; Apatite; Logistic regression

\section{Introduction}

Fossil marine bio-apatites from conodonts teeth; small animals that lived in ancient seas, can store a record of the content of paleoseawater of arsenic and lead [1]. This can then be compared statistically to the arsenic and lead contents in contemporaneous human teeth [2] and to the amounts of these metals found in rocks [3]. A tipping point is a statistically determined amount reached at which small changes become big enough to cause a large change. In biology the term tipping point refers to oscillating biological systems which cease to oscillate and consequently the organism dies. Here we use statistical methods to compare the tipping points for arsenic and lead in conodonts and contemporaneous human tissues [2].

\section{Materials and Methods}

\section{Sample preparation}

Samples of rocks and Conodonts teeth from New Mexico weighing $\sim 1.000$ to $\sim 2.000$ grams were dried crushed manually using a pestle and mortar. The samples were then pulverized using a SPEX mixer mill with carbide vessel and mixing balls. One thousand to 2.000 grams of the sample were weighed and digested using a mixture of $3 \mathrm{ml}$ concentrated nitric acid $\left(\mathrm{HNO}_{3}\right)$ and $2 \mathrm{ml}$ concentrated hydrochloric acid $(\mathrm{HCl})$. Samples were digested using DigiPrep heating block equipped with temperature controller at $95^{\circ} \mathrm{C}$ for about two hours. After digestion was completed, samples were filtered ( 0.45 micron) and brought to final volume " $25 \mathrm{ml}$ ".

\section{CP-OES analysis}

Digested samples were transferred into $15 \mathrm{ml}$ glass test tubes and were setup on the Inductively Coupled Plasma- Optical Emission Spectroscopy (ICP-OES) (PerkinElmer, Optima 5300DV ICP-OES and for Hg FIMS) autosampler. The system was optimized using mercury optical alignment and manganese $(\mathrm{Mn})$ view touch alignment.

\section{Statistical methods}

The tipping point in terms of arsenic $(\mathrm{As})$ and lead $(\mathrm{Pb})$ defines the concentrations of each which would compromise the natural biological rhythms of an animal beyond recovery as described in the introduction. The $\mathrm{Pb}$ cut score is defined [2] represents the amount $\mathrm{Pb}$ found in our previous study in human subjects residing in the Four Corner Region of New Mexico, the As cut score is facilitated by the scatter plot of As concentrations versus the $\mathrm{Pb}$ concentrations in the samples of this study. The extreme As concentrations include that of a human brain from Chile; the effect of As in Chilean subjects is well documented [4]. We selected the samples as best representing values for analysis in the model used. With this binary, a statistical method that is a data type which describes binary variables, which can take only two possible values, here either extreme As or $\mathrm{Pb}$ concentrations, we use logistic regression that is a statistical method for analysing a dataset in which there are one or more independent variables here $\mathrm{As}$ or $\mathrm{Pb}$, that determine an outcome, to obtain the probabilities of exceeding the tipping point versus geological time and versus the concentrations of $\mathrm{As}$ and $\mathrm{Pb}$ separately. P-values $£ 0.05$ are considered statistically significant for the relationships of the tipping point with period, here As concentration and $\mathrm{Pb}$ concentration.

\section{Results}

In the present study we present a statistical analysis as defined in the method section to show the relationship between period that is a time span of approximately 300 million years and the concentration of $\mathrm{As}$ and $\mathrm{Pb}$ in the environment, the result of geochemical enrichment, and in teeth the result of biological enrichment in New Mexico USA, (Figure 1). The time (period) in years is shown in Figure 2. Tipping point defined as exceeding $\mathrm{Pb}$ or As cut points. Periods are $\sim 300$ million years for Conodonts to -50 years for humans expressed on a $\log 10$ scale. There is significant decline in the probability of exceeding the tipping point over geological time $(\mathrm{P}=0.01)$ and the probability of

*Corresponding author: Appenzeller O, New Mexico Health Enhancement and Marathon Clinics Research Foundation, Albuquerque, NM, USA, Tel: +1 505-8412800; E-mail: ottoarun12@aol.com

Received April 30, 2018; Accepted May 23, 2018; Published June 10, 2018

Citation: Qualls C, Lucas SG, Ali AM, Appenzeller O (2018) Tipping Points: A Statistical Comparison between Humans and Conodonts. J Biom Biostat 9: 396. doi: 10.4172/2155-6180.1000396

Copyright: @ 2018 Qualls C, et al. This is an open-access article distributed under the terms of the Creative Commons Attribution License, which permits unrestricted use, distribution, and reproduction in any medium, provided the original author and source are credited. 


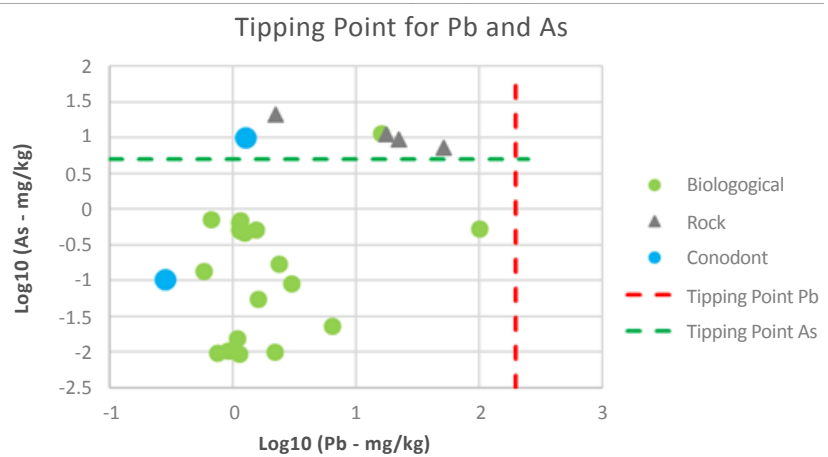

Figure 1: Scatter plot of $\log _{10}$ of As versus $\log _{10}$ of $\mathrm{Pb}$ for Conodonts (blue circle), Biological samples (green circle) and Rock samples (grey triangle). Tipping point for $\mathrm{Pb}$ (dashed red line) in reference [3] and tipping point for As (dashed green line) determined herein.

\section{Tipping Point Period}

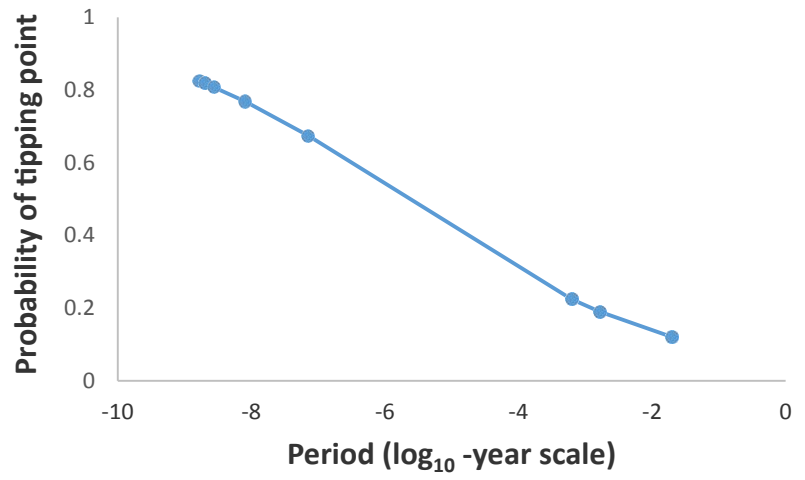

Figure 2: Probability of exceeding tipping point versus time period.

reaching the tipping point for $\mathrm{As}$ and $\mathrm{Pb}$ is given in Figure 3. Tipping point defined as exceeding $\mathrm{Pb}$ or As cut points. Concentrations of As and $\mathrm{Pb}$ range approximately from 0.01 to $100 \mathrm{mg} / \mathrm{Kg}$ expressed on a $\log 10$ scale. The probability of exceeding the tipping point significantly increases with increasing As concentration $(\mathrm{P}=0.01)$ and increasing $\mathrm{Pb}$ concentration $(\mathrm{P}=0.04)$. The concentrations of a $50 \%$ probability of exceeding the tipping point are $1.6 \mathrm{mg} / \mathrm{Kg}$ for As (dashed green line) and $3.2 \mathrm{mg} / \mathrm{Kg}$ for $\mathrm{Pb}$ (dashed red line).

\section{Discussion}

The Conodonts in our study were obtained from the Pennsylvanian Atrasado Formation of central new Mexico, about 305 million years old. Conodonts were small animals that had teeth containing the same chemicals as those of modern humans [1]. Such biogenic apatite dating to $\sim 300$ million years ago provides insights into the composition of metals in ancient teeth, gleaned from sea water that can be compared to that found in modern human teeth accumulated from food

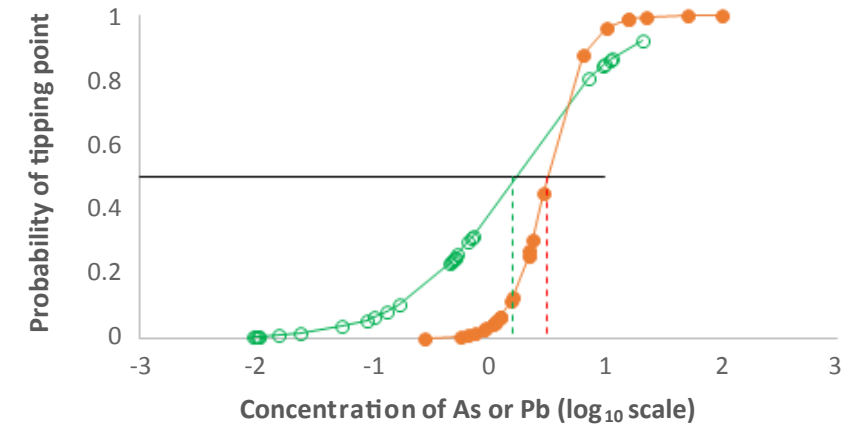

Figure 3: Probability of exceeding tipping point versus concentration of As (green curve) or $\mathrm{Pb}$ (red curve).

and modern environments. Here we used the tipping point for As determined in Figure 1 and the known effect of As on humans in Chile [4] to model the tipping point for As. Four rock samples, 1 Conodont sample and one other biological sample were above the tipping point for As. This implies that ancient seas contained high levels of As which also occurred in Conodont teeth and which was leached from rocks; a biogenic enrichment as determined using statistical modeling. Our results shown in Figure 2 give the probability of reaching the tipping point for $\mathrm{Pb}$ or As over geological time periods. We show that there is a significant decline in reaching the tipping point with time $(\mathrm{P}=0.01)$ implying that the sources of these neurotoxic metals in modern teeth have decreased such that $\mathrm{Pb}$ and As no longer accumulate in human apatite as it did in the apatite of Conodont teeth. Figure 3 shows the probability of exceeding the tipping point for $\mathrm{As}$ and $\mathrm{Pb}$ concentrations in teeth. The probability of exceeding the tipping point increases significantly with increasing As concentration $(\mathrm{P}=0.01)$ and increasing $\mathrm{Pb}$ concentration $(\mathrm{P}=0.04)$. This suggests that the toxic effects of these metals may be additive that is accumulation of both together is worse than accumulation of one only. However, tipping points are statistical models only which allow the estimation of eventual harm to humans arising from environmental neurotoxins as has been demonstrated previously [2,3]. Their usefulness is limited by the geographical area from which the material for analysis was obtained and time period of observation; herein 300 million years.

\section{References}

1. Trotter JA, Eggins S M (2006) Chemical systematics of conodont apatite determined by laser ablation ICPMS. Chemical Geology 233: 196-216.

2. Qualls C, Kornfeld M, Joste N, Ali AM, Appenzeller O (2016) MPV17-related hepatocerebral mitochondrial DNA depletion syndrome (MPV17-NNH) revisited. eNeurologicalSci 2: 8-13.

3. Qualls C, Ali AM, Lucas SG, Lombardi G, Appenzeller O (2016) Geochemica and Biological Enrichments with Toxic Metals; Anthropogenic Effects. J Environ Anal Toxicol 6: 419.

4. Schlebusch CM, Gattepaille LM, Engström K, Vahter M, Jakobsson M, et al (2015) Human adaptation to arsenic-rich environments. Mol Biol Evol 32:15441555. 